\title{
Hantavirus: Medidas de prevención y manejo ambiental
}

\author{
M.V. CARLOS PAVLETIC B. ${ }^{1}$
}

\section{HANTAVIRUS: ENVIRONMENTAL MEASURES FOR PREVENTION}

\begin{abstract}
Environmental measures to prevent contact with rodents and its excretion are the most important actions in order to protect the human beings from acquiring hantavirus infection, specially in rural areas where the reservoir of rodents is endemic.
\end{abstract}

Key words: Hantavirus; Rodents; Reservoir; Prevention.

Como se sabe, una de las características principales de los hantavirus es que requieren de un roedor como reservorio natural. Se ha determinado también, que en general, son los roedores silvestres los que actúan como reservorios, eliminando el virus por sus excretas (fecas, orinas y salivas), perpetuándolo en la naturaleza, a través de la mantención de un número de roedores infectados.

Por otra parte, se sabe que los roedores se distribuyen ampliamente en la naturaleza y tienen la capacidad de prosperar en diferentes hábitats. En condiciones ambientales favorables, estos animales pueden alcanzar altas densidades poblacionales, factor este último, que puede favorecer su contacto con el hombre, especialmente cuando los roedores buscan alimentos y refugio cerca de las habitaciones del hombre. Esto es aún más cierto si consideramos que la erradicación de los roedores silvestres es inconveniente desde el punto de vista ecológico, dado su rol en la cadena trófica, e imposible desde el punto de vista práctico, dado el gran número de especies implicadas, su amplia distribución y su abundancia en términos numéricos.

De acuerdo a lo anterior, y considerando que las vías más probables de transmisión del virus al hombre son la inhalación, el contacto con las conjuntivas y la ingestión de agua o alimentos contaminados con excreciones de roedores infectados, obviamente la medida de prevención primaria más importante y fundamental que se debe aplicar, es evitar el contacto del hombre, sus alimentos y viviendas con los roedores y sus excretas.

Así, para lograr concretar esta medida básica de prevención, las actividades deben estar orientadas a aplicar las estrategias de control ambiental que permitan en forma efectiva reducir el contacto de los roedores con el hombre.

Las medidas de control recomendadas para estos casos son las de saneamiento básico habitual para el control de roedores y están orientadas a evitar en lo fundamental, que estas especies encuentren fuentes de alimentos y condiciones favorables para su refugio, reproducción y anidación en las viviendas de las personas o en sus alrededores.

1 Departamento de Programas sobre el Ambiente, División de Salud Ambiental, Ministerio de Salud de Chile. 


\section{Medidas específicas para el control de roedores}

Se debe considerar que en las áreas rurales, los roedores, especialmente los silvestres, en forma normal tienden a vivir en sus hábitats naturales, alejados del hombre. Sin embargo, en situaciones anormales adversas como son la falta de alimentos, las bajas de temperaturas y otros, tienden a buscar refugio y alimentos en las construcciones que el hombre ha instalado, cercanas a sus ambientes naturales. Esta situación que puede ser cíclica durante las estaciones del año, con énfasis en regiones donde los cambios climáticos son marcados y rigurosos, se ve acentuada cuando algún factor ambiental provoca un aumento anormal de la densidad poblacional de roedores.

Teniendo presente la situación anteriormente señalada y a objeto de reducir la posibilidad de atracción, ingreso y asentamiento de roedores a las viviendas y construcciones, especialmente las ubicadas en zonas rurales, se deben tomar las medidas tendientes a eliminar los factores que posibiliten su anidación, reproducción y alimentación.

\section{- Estructura y ordenamiento de la vivienda}

Como se sabe los roedores poseen, de acuerdo a la especie, características particulares tales como una gran elasticidad, capacidad para trepar y roer materiales duros. Estas habilidades les permiten penetrar por hendiduras de pequeño calibre, subir a las estructuras de gran pendiente, aun por alambres, y socavar estructuras sólidas con sus incisivos. Por esta razón en la construcción de las viviendas las murallas, cimientos y techos deben considerar materiales y estructuras que no tengan orificios ni hendiduras por los que puedan penetrar los roedores. Se debe tener presente que los roedores pueden penetrar entre ventanas y puertas o por los marcos de éstas mal ajustadas, por hendiduras y orificios entre las cañerías de alimentación de agua, gas, electricidad y otros servicios. Las entradas de ventilación, chimeneas y ductos de alcantarillado deben estar protegidos con mallas de bizcocho de menos de un centímetro cuadrado. Colocar dispositivos que eviten que ellos trepen a los entretechos, dotar a las construcciones de pisos herméticos sin aberturas y que no posean espacios bajo la vivienda susceptibles de servir de madrigueras.

En las casas existente se deben ubicar y sellar todas las rendijas de más de dos centímetros de abertura, tanto en el interior como en el exterior de la estructura de la edificación, con materiales como planchas de acero, viruta de acero, cemento u otro material resistente a la acción de los roedores. Se deben adoptar todas las medidas para proteger con dispositivos antirratas todos las estructuras existentes susceptibles de servir de vía de entrada o lugar de colonización, como los descritos anteriormente. Estas medidas son de especial importancia en aquellos recintos en que se almacenan alimentos, los que en general, representan un elemento atractivo para los roedores.

En lo posible, las edificaciones deben tener una base sólida de a lo menos $30 \mathrm{~cm}$ de alto y una profundidad de $20 \mathrm{~cm}$, evitando que queden hendiduras entre el cimiento y la estructura del edificio, a objeto de evitar la instalación de madrigueras bajo estas estructuras, las que generalmente son de difícil erradicación. En las regiones en las que por razones climáticas, de disposición de materiales de construcción u otras, no sea posible la construcción de esta base sólida, se recomienda edificar sobre pilotes, con una altura que permita realizar un aseo prolijo y frecuente bajo la vivienda. El piso de estas construcciones debe ser hermético y los pilotes de sustentación deben ser provistos de dispositivos que eviten el ascenso de los roedores, como son los conos metálicos invertidos.

Los lugares poco visitados, con materiales acumulados y removidos con poca frecuencia, son los preferidos por los roedores para instalar sus nidos. Por esta razón es de suma importancia eliminar del interior de los recintos todos los elementos en desuso que puedan servir para la anidación de los roedores. Mantener limpios y ordenados los recintos en que se almacenan materiales, como son sótanos, entretechos, mansardas o sitios similares. Se recomienda limpiar y reordenar los materiales acumulados en forma frecuente.

En el exterior se debe mantener limpio y despejado un radio de 30 metros alrededor de la 
Hantavirus: Medidas de prevención y manejo ambiental - C. Pavletic B.

vivienda. Evitar la acumulación de todo tipo de materiales de desecho o en desuso. En lo posible, ubicar la leña, paja u otros materiales, a lo menos a 30 metros de la vivienda y sobre tarimas de $20 \mathrm{~cm}$ de alto, tratando de mover este material periódicamente.

Teniendo en cuenta que una amplia variedad de roedores construye sus nidos entre los arbustos y la vegetación espesa que les proporciona refugio y protección tanto de los predadores como de los factores climáticos, es necesario mantener alrededor de las edificaciones el pasto corto y eliminar toda vegetación que pueda servir de refugio o fuente de alimento a los roedores. Sin embargo, cuando exista abundante cantidad de vegetación alrededor de la vivienda y existan evidencias de roedores, es conveniente aplicar rodendicidas en el exterior de la vivienda, a lo menos siete días antes de proceder a desmalezar los alrededores. Este período de tiempo permitirá que los ratas que consuman el veneno mueran antes de comenzar la limpieza. Como medida complementaria antes de la limpieza se deben sellar las posibles entradas de la edificación para evitar que los roedores que sobrevivan migren a su interior en busca de refugio.

\section{- Manejo y protección de alimentos y agua}

Las fuentes de alimentos y agua son los elementos más importantes para la mantención de las funciones vitales de los roedores, la obtención de ellos es crítica para su supervivencia. Por esta razón estos animales tienen altamente desarrollado el sentido del olfato, lo que les otorga una especial capacidad para detectar la presencia de alimentos; esto, unido a la capacidad de trepar, cavar, y pasar por espacios reducidos, les permite acceder a ellos con gran facilidad.

Teniendo en cuenta las característica anteriormente señaladas, sin duda, el limitarles la oferta de alimentos y agua es una de las medidas más efectivas para el control de estas especies. Por esta razón, en toda circunstancia se deben mantener todos los alimentos almacenados en lugares o envases a prueba de roedores. En el hogar se deben almacenar los alimentos en muebles herméticos a prueba de roedores y en lo posible, además, en envases cerrados, de material rígi- do, resistentes a mordidas de roedores. Es necesario también evitar que restos de alimentos queden al alcance de los roedores, por tanto, se debe impedir la acumulación de ellos, lavando en forma inmediata los platos de comida usados y depositando los restos de comida en tarros de basura cerrados, tanto en el interior como en el exterior de la vivienda. En el área rural, donde es factible alimentar a los animales domésticos con los restos de alimentos, se debe tratar, en lo posible, que éstos sean consumidos de inmediato por los animales, cuidando no dejar restos a disposición de las ratas. Otra forma de disposición de los restos de alimentos es el enterramiento.

Si bien, generalmente el acceso al agua es más fácil para los roedores, especialmente en áreas rurales de la zona sur, con abundantes fuentes de este elemento, se debe tener la precaución de mantener protegidas las fuentes de abastecimiento de agua para la bebida, de modo de evitar que ésta sea contaminada por estos animales. En lugares en que no se cuenta con agua potable, se debe hervir o desinfectar el agua con la aplicación de cloro comercial, cinco gotas por litro de agua. El agua debe ser, en lo posible, cristalina y debe permanecer con cloro a lo menos veinte minutos antes de usarla como bebida. En caso de aguas no cristalinas, se deben dejar decantar antes de adicionar el cloro, aplicando una doble cantidad de cloro que la especificada para aguas limpias.

Las bodegas de alimentos deben ser de una estructura tal que impida el ingreso de roedores, aplicándose a ellas todas las medidas de control de estructura señaladas anteriormente para las viviendas. En casos de almacenaje de grandes cantidades de alimentos, se debe considerar el uso de tarimas que eviten la formación de lugares de anidación, permitan el aseo del recinto y el movimiento frecuente de los productos almacenados.

\section{- Manejo de residuos sólidos}

Los residuos sólidos domésticos, así como los residuos orgánicos producidos por actividades comerciales, son una importante fuente de alimentos para los roedores. Así también, los lugares de disposición no sanitaria de estos resi- 
duos constituyen hábitats propicios para su proliferación, proporcionando el alimento y cobijo suficientes para su crecimiento, mantención y reproducción.

En consideración a lo anterior, los residuos deben ser manejados sanitariamente desde su generación hasta su disposición final, pasando por los procesos intermedios de almacenaje y transporte. Así se debe acumular todo residuo susceptible de ser utilizado como alimento por estos animales en contenedores o salas herméticas cuando se trate de grandes volúmenes, especialmente acondicionados para este efecto y que cuenten con los dispositivos necesarios para evitar el ingreso de roedores. Por otra parte, tanto los recintos como los contenedores para el almacenamiento transitorio de residuos, deben ser lavables de manera de evitar que se conviertan en un foco de atracción de ratas y otros vectores, producto de los olores o detritus acumulados en ellos. Así mismo el transporte de estos residuos debe ser en vehículos o dispositivos especialmente adaptados para el efecto de modo de evitar la dispersión de ellos durante esta etapa del proceso.

En los hogares, las basuras deben ser depositadas en tarros que tengan tapas cuyo cierre evite el ingreso de roedores. Las basuras deben ser depositadas en éstos inmediatamente después de producidas y mantenidas allí hasta su recolección en el caso que exista el servicio o hasta su disposición final. En caso de no contar con sistema domiciliario de recolección de basuras, se debe utilizar los sistemas individuales de disposición. Estos, generalmente se implementan en base al enterramiento de la basura. Para estos efectos es conveniente hacer un hoyo de una profundidad y capacidad de acuerdo a la cantidad de residuos a depositar y el tiempo previsible de uso. Se debe considerar, para el caso de una vivienda, a lo menos un metro de profundidad y cubrir con una capa de tierra cada vez que se dispongan residuos en él. Se debe tener la precaución de ubicar estos depósitos de basura a lo menos a veinte metros aguas abajo de un pozo o noria de agua para la bebida, a objeto de evitar la probable contaminación de la fuente de agua con los líquidos percolados que producen los acúmulos de residuos orgánicos.

A fin de obtener cambios permanentes en esta área, es fundamental educar y capacitar a la población a través de campañas participativas de recolección, transporte y manejo de basuras, con el propósito que internalice la importancia de esta actividad en el mejoramiento de su calidad de vida y permita incorporar sistemas individuales de disposición sanitaria de los residuos domésticos. En los sectores rurales que no cuentan con servicio de recolección crítico evitar la formación de basurales descontrolados y la de microbasurales en sectores urbanos. Se debe además, capacitar a la comunidad en la detección y denuncia de la presencia de éstos a las municipalidades para que procedan a su eliminación. Así también, la comunidad debe colaborar con las autoridades en la adopción de medidas tendientes a obtener la habilitación y construcción de rellenos sanitarios en todas aquellas localidades en que esto sea factible desde el punto de vista técnico y operativo, lo que contribuirá a evitar la generación y resurgimiento de vertederos no sanitarios y microbasurales.

\section{- Medidas complementarias}

Las medidas más efectivas para el control de roedores son, sin duda, la aplicación permanente de las buenas prácticas de manejo sanitario, a objeto de reducir las posibilidades de obtención de alimento y abrigo para estos animales. En esta perspectiva, y como medida permanente de control, es importante la introducción del concepto "a prueba de roedores" en la construcción de las edificaciones, lo que implica considerar en estos proyectos la introducción de implementaciones estructurales que eviten la penetración de estos animales a los edificios y la formación de lugares aptos para la anidación. Como medida de emergencia y en casos especiales se debe considerar la aplicación de rodendicidas. Sin embargo, se debe tener presente que la aplicación de estos productos no es, en sí misma, una solución eficaz al problema y sólo debe ser entendida como una medida complementaria a las normas de ordenamiento del medio. La aplicación de rodendicidas debe estar limitada a la protección de edificaciones, ya sea en forma interna o en perímetros de protección externa controlada, evitando la distribución indiscriminada de ellos en el ambiente. Estos 
Hantavirus: Medidas de prevención y manejo ambiental - C. Pavletic B.

productos siempre deben ser usados de acuerdo a las instrucciones del fabricante, teniendo especial cuidado de ubicarlos en lugares fuera del alcance de los niños y de los animales domésticos. Se debe tener presente junto a la aplicación de rodendicidas, especialmente en el interior de las edificaciones, la fumigación con pesticidas para el control de las pulgas que abandonan los cadáveres de los roedores.

\section{Medidas a adoptar por grupos de riesgo}

Para los efectos de la infección por hantavirus se consideran grupos de riesgo aquellas personas que por su actividad tienen contacto frecuente con roedores o con lugares potencialmente infestados por éstos, como son: desrratizadores, trabajadores portuarios, usuarios de campamentos de trabajo, personas que en sus actividades recreativas acampen al aire libre o en sectores de camping no habilitados oficialmente. Para estos grupos se deben conocer y aplicar las siguientes recomendaciones:

* Las personas que deban ingresar a lugares cerrados potencialmente infestados por roedores, deberán hacerlo utilizando todos los elementos de protección personal, incluida la protección respiratoria con máscaras o equipos con presión positiva, ambos provistas de filtros de alta eficiencia (HEPA).

* Los campamentos, tanto de trabajo como recreacionales, no deben instalarse en lugares en que hallan evidencias de la existencia masiva de roedores, como son la presencia de heces, roedores muertos o madrigueras. Lugares cercanos a acumulación de escombros, basuras, paja o maderas no son aptos para la instalación de campamentos.

* En los campamentos el almacenamiento de alimentos y agua debe hacerse en envases herméticos a prueba de roedores. En caso de existir bodega de alimentos, ésta debe cumplir con las especificaciones de construcción que impidan el ingreso de roedores. El agua para bebida, aseo dental, cocina y lavado de platos debe provenir de una fuente de agua potable o en su defecto deberá ser desinfectada por ebullición o por la aplicación de cloro o yodo.
* En los campamentos deben depositarse las basuras en tarros cerrados a prueba de roedores y su disposición final debe realizarse por enterramiento y a una distancia no menor de 300 metros de las instalaciones.

* En los campamentos de trabajo que se establecen por un tiempo prolongado, se recomienda la aplicación de rodendicidas como medida complementaria a las de saneamiento básico.

* Los recintos a los cuales deban ingresar personas y que hayan estado cerrados por un tiempo prolongado, previo a su uso, deben ser ventilados por al menos una hora.

* Las instalaciones de albergues de los campamentos deben cumplir con las condiciones de construcción que eviten el ingreso de roedores al interior. Las carpas deben contar en lo posible con piso y se debe evitar poner los sacos de dormir en contacto directo con el suelo.

\section{Medidas de desinfección a considerar en situaciones de riesgo}

Teniendo en cuenta que los roedores contaminan el ambiente a través de sus excretas, se deben tomar precauciones durante las actividades de aseo de los lugares potencialmente infectados y la manipulación de roedores aplicando, cuando la situación lo amerite, soluciones desinfectantes. Dada la labilidad del virus, la aplicación de una dilución de dos cucharadas soperas de cloro al $10 \%$ en 5 litros de agua resulta efectiva como desinfectante. Se deben tener presente las siguientes recomendaciones:

* Durante las actividades de aseo y manipulación de roedores se deben usar en forma permanente guantes de goma gruesos. Una vez finalizadas las labores de aseo y/o manipulación, se recomienda lavar las manos con los guantes puestos en una solución detergente y desinfectante, para luego sacarlos, y lavar las manos con abundante agua y jabón.

* En recintos cerrados en que exista acumulación de polvo, se debe rociar o fumigar en forma abundante el recinto, antes de limpiar, con una solución de detergente y desinfectante, lo que evitará la formación de aerosoles 
durante las actividades de aseo. Las superficies de muebles, clósets, mesas y similares, deben ser limpiadas con un paño humedecido en solución desinfectante.

* Los alimentos, materiales u otros elementos con evidencias de haber sido contaminados por roedores, deben eliminarse en doble bolsa plástica previa fumigación con solución desinfectante. La disposición final deberá ser por enterramiento a no menos de $60 \mathrm{~cm}$ o por incineración.

* Previo a la manipulación, de roedores muertos y de desechos de roedores o sus nidos, éstos deben ser rociados o fumigados en forma abundante con solución desinfectante. Una vez desinfectados se deben colocar en doble bolsa plástica y posteriormente deben ser enterrados o incinerados.

\section{Medidas especiales}

No existen evidencias que indiquen la necesidad de establecer medidas especiales en las zonas afectadas. Por esta razón no se justifican medidas restrictivas a las actividades turísticas y recreacionales, como tampoco se justifica la instalación de barreras sanitarias, ni restricciones al transporte de alimentos. Por tanto la presencia de casos de infección por hantavirus o animales infectados no requiere de medidas restrictivas de ninguna naturaleza y el cumplimiento de las recomendaciones anteriormente señaladas es suficiente para evitar el contagio.

\section{RESUMEN}

Considerando el hábitat principal del reservorio y las vías de transmisión del SPH, las medidas de prevención deben estar orientadas a evitar el contacto de las personas con los roedores y sus excretas, especialmente en las áreas rurales.

\section{BIBLIOGRAFIA}

1.- ORGANIZACION PANAMERICANA DE LA SALUD. Hantavirus en las Américas: Guía para el diagnóstico y tratamiento, la prevención y el control. Washington, DC. OPS. 1999.

Correspondencia a:

Carlos Pavletic Brevis

Fax. 56(2): 6397110

Email:cpavletic@netline.cl 